\title{
DEBRIS-FRETTING TEST OF COATED AND UNCOATED ZR-1\%NB CLADDING
}

\author{
Marcin Kopeć ${ }^{a, *}$, Martina Malá $^{a}$, Ladislav CvrČEK ${ }^{b}$, Jakub KrejČí ${ }^{c}$ \\ ${ }^{a}$ Research Centre Řě̌, Hlavni 130, 25068 Husinec- ̌̌ě̌, Czech Republic \\ ${ }^{b}$ Czech Technical University in Prague, Faculty of Mechanical Engineering, Deparment of Materials Engineering, \\ Karlovo náměsti 13, 12135 Prague 2, Czech Republic \\ ${ }^{c}$ UJP PRAHA a.s., Nad Kamínkou 1345, 15610 Prague - Zbraslav, Czech Republic \\ * corresponding author: marcin.kopec@cvrez.cz
}

\begin{abstract}
Debris fretting is one of the most significant fuel rod failure causes. An approach to mitigate this is to apply special coatings on the surface of the cladding that are supposed to increase the wear resistance. This paper summarizes the experiments performed in Research Centre Řež on fuel cladding tube specimens. The tube segments made of uncoated and coated $\mathrm{Zr}-1 \% \mathrm{Nb}$ alloy were exposed to fretting tests simulating the wire-debris vibrations impact on cladding during the reactor operation. The goal of these tests is to obtain results about the differences in wear resistance of uncoated and coated specimens. This paper shows the testing procedure in the air at room temperature and obtained impact markings on the specimens' surfaces.
\end{abstract}

KEYwords: Cladding, fretting, nuclear fuel.

\section{INTRODUCTION}

The leaking fuel rods are an issue having been solved for a long time and remaining still relevant. In most cases the root cause of the failure is found which is visible in Figure 1. Nevertheless, in some causes the root cause cannot be identified at the power plant and then it is necessary to cool down the assembly in a spent fuel pool for few years to decrease its activity, then transport it to a hot cell facility, and perform detailed post-irradiation examination. This is associated with higher costs. The leaking fuel rod phenomenon is associated also with possible deteriorative handling and storage. This can stand as a challenge for utilities, who either have to invest in the repair of fuel assembly or loose space in their spent fuel pools. Indirectly this issue affects also the fuel vendors when their fuel product is not so reliable and needs improvement. Generally, the improvement can be beneficiary for the whole nuclear fuel market but the costs, to reach it, are excessive and may have been pointless. The NEI report from 2016 specifies the leaking fuel rod costs as $\$ 1.5 \mathrm{~B}$ per reactor [1] globally.

One of the most important degradation mechanism of a nuclear fuel rod is the fretting wear coming from the flow-induced vibrations (FIV). The weak wear resistance of the cladding material can lead to its rupture. According to the Nuclear News (in cooperation with EPRI), for the year 2010, the majority of failed fuel rod causes in the U.S. was related to the wear problem [2].

The more renowned mechanism of wear damage is grid-to-rod fretting. Some studies and models have addressed this phenomenon [3 5], including power plant experiences [6]. On the opposite side there is the debris fretting failure mechanisms. The studies concerning the debris impact onto the fuel assembly are limited to new designs of anti-debris filters mounted in the fuel assembly bottom nozzles, e.g. filtering wires of diameter more than $1 \mathrm{~mm}$ or plates of the thickness of more $0.3 \mathrm{~mm}$ and lengths reaching more than $10 \mathrm{~mm} \mathrm{[7.} \mathrm{An} \mathrm{attempt} \mathrm{to} \mathrm{limit} \mathrm{the} \mathrm{problem}$ is the introduction of the Foreign Material Exclusion (FME) policy, which is more and more incorporated by the nuclear power plants into their internal regulations. This, although, can proof ineffective in the case of object of diameter less than $1 \mathrm{~mm}$ and less than $10 \mathrm{~mm}$ in length, e.g. wires coming from the maintenance of the power plant. The FIV in those cases gets into high-frequency vibrations. Hence the force load of a single debris-cladding contact is relatively very small, the numerous impacts can lead to fretting wear when the affected range is limited. Another approach lowering the debris-impact onto the fuel cladding integrity is the introduction of coatings on the cladding surface, which are usually formed as a very thin film (microns) of highly wear-resistant material. This issue is directly related to the Accident Tolerant Fuels (ATF) concepts, being the matter of a research world widely. The most known is the CrN layer coating which dates back to the 70' and has its own history in e.g. Halden Reactor Project (HRP) activities [8]. Those days, the coatings and the process of their application, were extremely costly and ineffective. With the development of technology and the research constantly pending in this field, the coatings' performance has been increased. Similarly the range of potentially useable material for coatings. No ultimate material has been specified and in the aim of mechanical tests is to select the group of the 


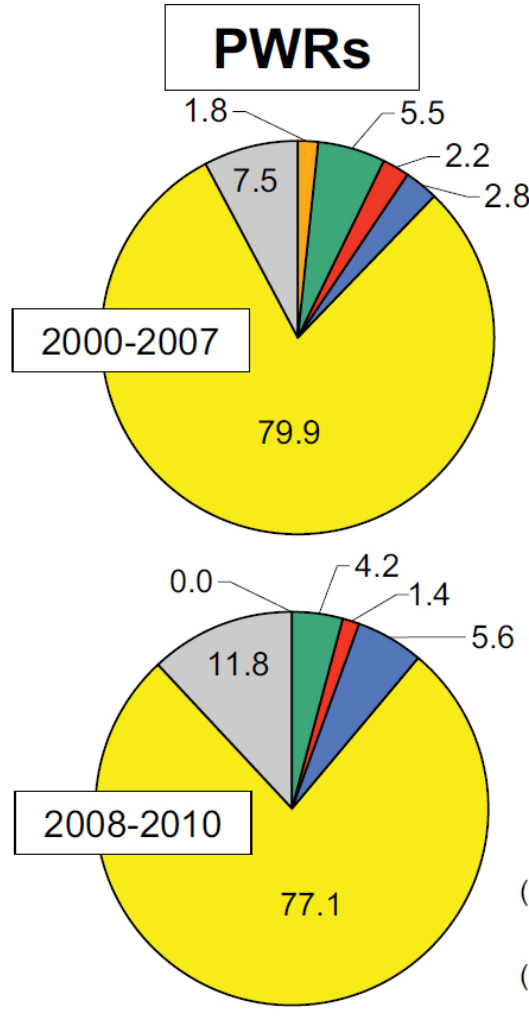

\section{BWRs $^{(2)}$}

\begin{tabular}{|c|}
\hline Mechanism \\
\hline $\begin{array}{c}\text { Grid-to-Rod } \\
\text { Fretting }\end{array}$ \\
\hline $\begin{array}{c}\text { Crud/ } \\
\text { Corrosion }\end{array}$ \\
\hline Duty Related \\
\hline Debris \\
\hline Fabrication \\
\hline Unknown \\
\hline
\end{tabular}

1.3
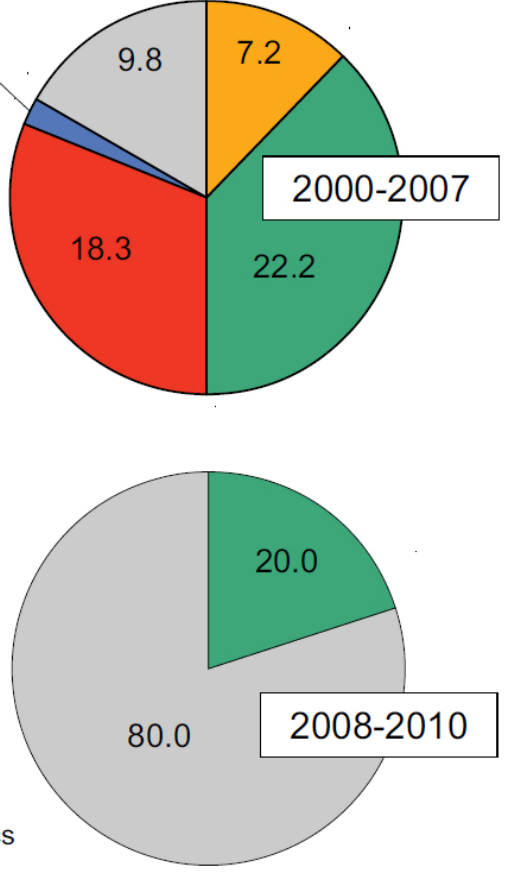

Figure 1. The percentages of nuclear fuel rod failure causes in U.S. for 2010 [2].

most promising in the view of their endurance also under the load of debris in high-frequency vibrations. Such process constitutes a qualification process for new ATF materials and new coatings on standard cladding materials. The R\&D tasks to specify the best accessible material is world widely ongoing - the fuel vendors are equally involved into this process as the research organizations [9, 10].

Research Centre Řež (CVŘ) has developed its own methodology for debris fretting of nuclear fuel cladding testing in dry conditions with the possibility to widen the spectrum for wet and high-temperature dry tests. In this way, it is possible to test and compare different types of ATF claddings, including even $\mathrm{SiC} / \mathrm{SiC}$ composites, which are supposed to withstand the debris impact even in elevated temperatures. In the cooperation with the Czech Technical University (CTU) in Prague and UJP Praha a.s. several types of coatings on standard $\mathrm{Zr}-1 \% \mathrm{Nb}$ cladding were tested for fretting wear resistance. All tests included the reference on the as-received specimen of $\mathrm{Zr}-1 \% \mathrm{Nb}$ cladding. This work presents the testing method and preliminary outputs of the materials' comparison.

\section{TESTING METHOD OF DEBRIS FRETTING WEAR}

As no standards have been found in the open literature for debris fretting wear testing as well as no models have been found for the prediction of the debris particle inside the reactor core during reactor operation, the authors decided to foreseen the potentially worst scenario. Hence it is on the verge of possibilities to model the behavior of the small wire particle inside the reactor core, the case where one of the ends of the wire is caught inside a fuel assembly spacer grid was selected. In this way, the second end exerts a repetitive load on the cladding surface, depending on the FIV of the particular fuel assembly. As the anti-debris filters capture foreign objects of ca. $1 \mathrm{~mm}$ in each dimension [7], a stainless steel wire of the diameter of $0.4 \mathrm{~mm}$ was specified for the fretting tests. The testing equipment can house as many as 8 specimens including the reference one. It is based on the rotation cycling of the foreign object imitator (i.e. wire) with the possibly constant radial speed of ca. 1000 RPM. The precise number of contacts between the foreign object imitator and the specimens are recorded with voltage circle closed by the wire and the specimen.

The wire has one free end that cyclically gets into smooth slide-contact with testing specimens. It is ensured by the bending of the used wire as can be seen in Figure 3a. To avoid sliding of the wire over the surface of the specimen, it is kept between two clamps which are leaving no more space than twice the diameter of the used wire. In this way, the slide-spot of the wire over the specimen is at the same level as the fastening of the wire itself, what can be seen in Figure 3b

The specimens are mounted symmetrically against the rotating shaft inside the testing equipment. The length of the wire is ca. $2 \mathrm{~mm}$ longer than the distance 


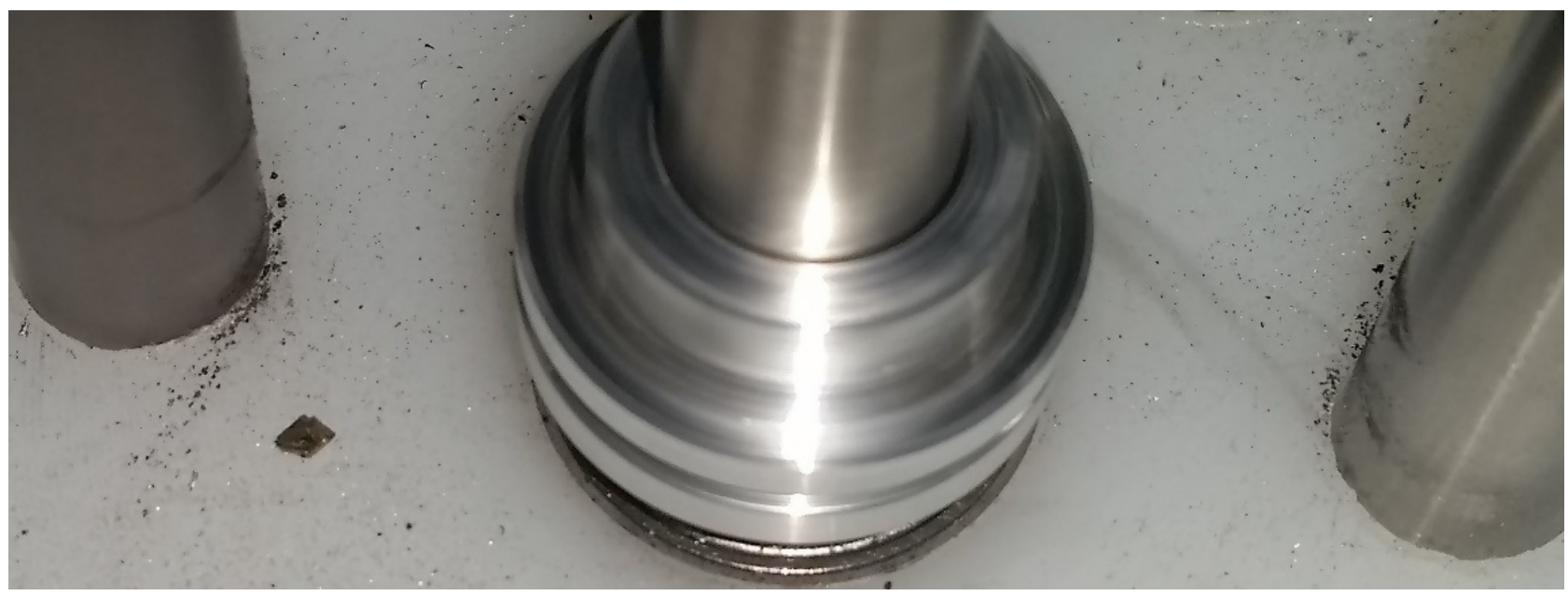

FIGURE 2. Testing equipment with 2 specimens in parallel testing: right - uncoated $\mathrm{Zr}-1 \% \mathrm{Nb}$; left - CrN-coated $\mathrm{Zr}-1 \% \mathrm{Nb}$.

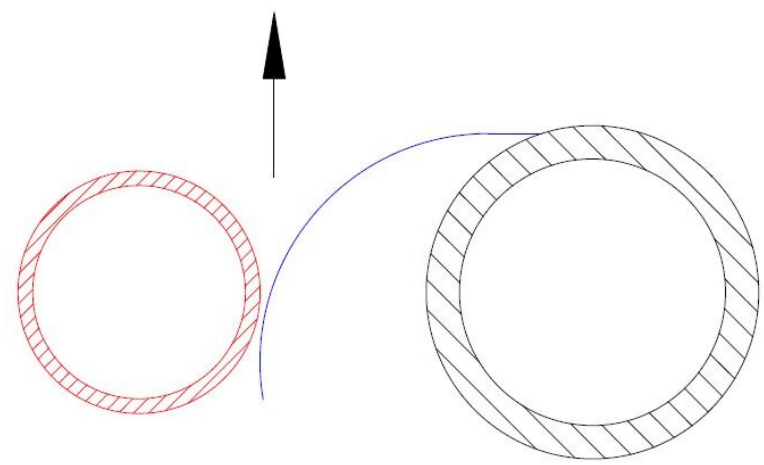

(a) Schematic upper view - specimen (red), wire (blue), the arrow shows wire's movement direction, black - pivot.

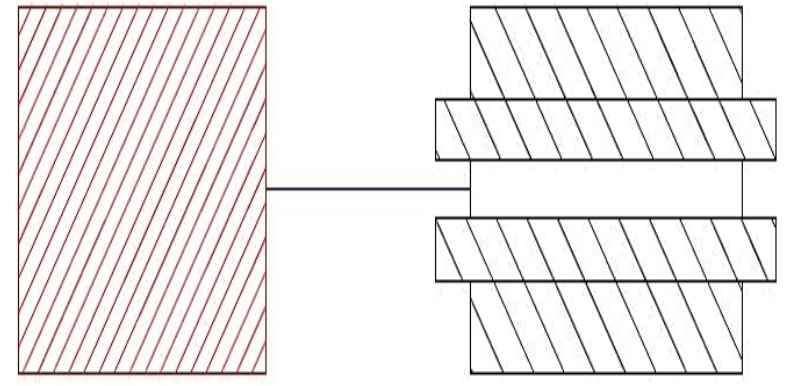

(b) Clamps (black) and wire positions.

Figure 3. The wire scheme.

between the shaft and the specimen. In this way, the equal angle distances between the specimens and the length of the wire ensures almost equal force that the wire exerts on the specimens' surfaces. What is more, the contact force is extremely low to keep the wire-specimen in the conditions that will enable free sliding of the wire against the specimen. The impact of additional coating layer thickness is due to the above negligible.

To keep the reference between each batch of testing specimens and to preserve the correlation between the various types of coatings, 4 -time ranges were specified: $120 \mathrm{~min}, 200 \mathrm{~min}, 350 \mathrm{~min}$, and $500 \mathrm{~min}$. The cycling of the specimens and the recording of the impact appearance is controlled from the computer. The equipment allows testing the specimen in wet condition up to $100{ }^{\circ} \mathrm{C}$. While mounted in a special chamber, it is able to run a couple-of-days long experiment in temperatures reaching up to $800{ }^{\circ} \mathrm{C}$ (dry environment). The hot cells are able to house a long-lasting experiment (50 days) in the furnace in temperatures reaching $1100{ }^{\circ} \mathrm{C}$ (dry environment). In these hot-cell conditions, irradiated samples can be tested. The testing in elevated temperatures is important for the candidates of Gen-IV cladding materials as $\mathrm{SiC} / \mathrm{SiC}$, which are meant to work in temperatures exceeding $800{ }^{\circ} \mathrm{C}$. Those materials should be able to withstand the conditions of possible accident, when the temperature could exceed $1000{ }^{\circ} \mathrm{C}[11$.

\section{Testing SPECIMENS OF COATINGS}

For the testing, there were selected five specimens of different Cr-based coatings, including the composite coatings. The coatings were prepared and applied at CTU in Prague in cooperation with UJP Praha a.s. The Cr-based coatings were deposited on outer surfaces of $\mathrm{Zr}-1 \% \mathrm{Nb}$ tubes by magnetron sputtering from $\mathrm{Cr}(99.6 \%)$ targets in the Hauzer Flexicoat 850 industrial system. Pure metallic chromium coatings were prepared in the argon atmosphere and ceramic $\mathrm{CrN}$ and $\mathrm{CrN}_{2}$ coatings in a gas mixture of argon and nitrogen at the deposition temperature of about $250{ }^{\circ} \mathrm{C}$. As the coatings to be tested, simple layers of pure chromium $(\mathrm{Cr})$, chromium nitride $(\mathrm{CrN})$ and super stochiometric chromium nitride $\mathrm{CrN}_{2}$. As the mul- 
ticomponent coatings were testerd chromium nitride and chromium $(\mathrm{CrN}+\mathrm{Cr})$ and super stochiometric chromium nitride and chromium $\left(\mathrm{CrN}_{2}+\mathrm{Cr}\right)$. Before deposition, the tubes were ultrasonically cleaned in acetone, ethanol, and demineralized water and dried with in furnace at $90{ }^{\circ} \mathrm{C}$. The tubes were placed then hanged into the vacuum chamber on rotating holders in the Flexicoat system where the tube surfaces were cleaned by ion etching in the argon plasma. This process removes the thin Zr-oxide and other impurities thus improving adhesion of the coating. The deposition parameters vary depending on the particular coating. A thin metallic Cr-layer was deposited on the substrate first when depositing ceramic coatings to improve adhesion. The thickness of the as-deposited coatings was measured with a Calotest (CSM, Switzerland). The resulting thicknesses are presented from the outermost coating towards the substrate in Table 1.

\begin{tabular}{llll}
\hline Coating & $\begin{array}{l}\text { Layer } \\
(\mu \mathbf{m})\end{array}$ & $\begin{array}{l}\text { Layer } \\
(\mu \mathbf{m})\end{array}$ & $\begin{array}{l}\text { Total } \\
(\mu \mathbf{m})\end{array}$ \\
\hline $\mathrm{Cr}$ & 18.6 & - & 18.6 \\
$\mathrm{CrN}$ & 16.4 & - & 16.4 \\
$\mathrm{CrN}_{2}$ & 10.7 & - & 10.7 \\
$\mathrm{CrN}+\mathrm{Cr}$ & 16.4 & 18.6 & 35.0 \\
$\mathrm{CrN}_{2}+\mathrm{Cr}$ & 10.7 & 18.6 & 29.3 \\
\hline
\end{tabular}

TABLE 1. Measured thicknesses of applied coatings.

\section{The PRELIMINARY OUTPUTS}

At first, the tested specimens and their fretting marks were visually examined. They have not been thoroughly measured yet. They are prepared for replicamethod measurements with the use of high-resolution scanning - 5 micron precision. Nevertheless, using the Vertex Automated Precision Measurement System it was possible to prepare good quality pictures of the fretting grooves. Those preliminary outputs already can show the increase in wear resistance when the coatings basing on $\mathrm{Cr}$ are applied. The tables below compare each batch of the tested specimens.

However, the surface treatments of "as received" uncoated and coated specimens are quite different, no additional improvement like polishing of coated specimens was applied. The tests were deliberately conducted in such conditions because of the fact, that any potential LTA assembly will house either both uncoated and coated fuel rods or will have only coated rods but will be placed next to uncoated assembly. No information was found about the planned additional treatment and the supposition is that in the case of debris contact, the coated specimen can be polished "freely" with the debris. This is to verify the behavior of the mixed-core, which can ease the change from regular fuel to ATF without the necessity to change the whole fuel batch at once. What is more, testing

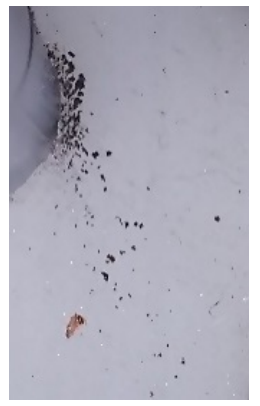

(a) Sediments after testing of $\mathrm{CrN}_{2}+\mathrm{Cr}$-coated $\mathrm{Zr}$ $1 \% \mathrm{Nb}$.

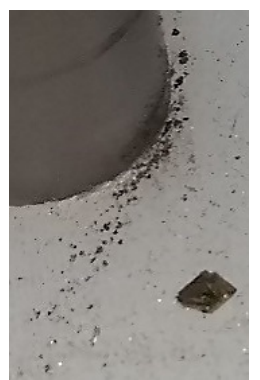

(b) Sediments after testing $\mathrm{CrN}$-coated $\mathrm{Zr}-1 \% \mathrm{Nb}$.

FiguRE 4. Sediments.

the specimens in "as received" state - both coated and uncoated - gives more information about the inherent strength of the coating. In this way, the potentially ultimate candidates' range can be limited.

A very important output that can be distinguished in those preliminary outputs are the rest-overs coming from the friction between the wire and the specimen. Their highest accumulation was observed by the $\mathrm{CrN}_{2}+\mathrm{Cr}$ composite coating and the $\mathrm{CrN}$ coating. As no such accumulation of particles was visible in the vicinity of reference specimen and as the length of the wire did not alter after all the tests, it is supposed that the sediment origins in the coated specimen. The most probable is the coating wear in the contact area but without breaking the coating structure. Figures $4 a$ and $4 \mathrm{~b}$ show sediment accumulation. The precise answer about the sediment can be delivered by microstructure analysis which is planned for the second half of 2019 - after the replica measurements.

\section{Conclusions}

The CVŘ has developed its own methodology and equipment for debris fretting testing of cladding materials. The testing equipment can be extended for tests in elevated temperature and long-lasting tests in temperatures exceeding $1000{ }^{\circ} \mathrm{C}$. In the cooperation with CTU in Prague and UJP Praha a.s. five different types of cladding materials were tested in the same conditions for their comparison. The photos obtained with the Vertex equipment clearly indicates the positive effect of coating application on the wear resistance of standard $\mathrm{Zr}-1 \% \mathrm{Nb}$ cladding. On the reference uncoated "as-received" samples the grooves from 


\begin{tabular}{|c|c|c|c|c|c|c|c|}
\hline \multicolumn{2}{|c|}{$120 \mathrm{~min}$} & \multicolumn{2}{|c|}{$200 \mathrm{~min}$} & \multicolumn{2}{|c|}{$350 \mathrm{~min}$} & \multicolumn{2}{|c|}{$500 \mathrm{~min}$} \\
\hline $\begin{array}{c}\text { CrN } \\
\text { coated }\end{array}$ & Uncoated & $\begin{array}{c}\mathrm{CrN} \\
\text { coated }\end{array}$ & Uncoated & $\begin{array}{c}\mathrm{CrN} \\
\text { coated }\end{array}$ & Uncoated & $\begin{array}{c}\text { CrN } \\
\text { coated }\end{array}$ & Uncoated \\
\hline
\end{tabular}

(2)

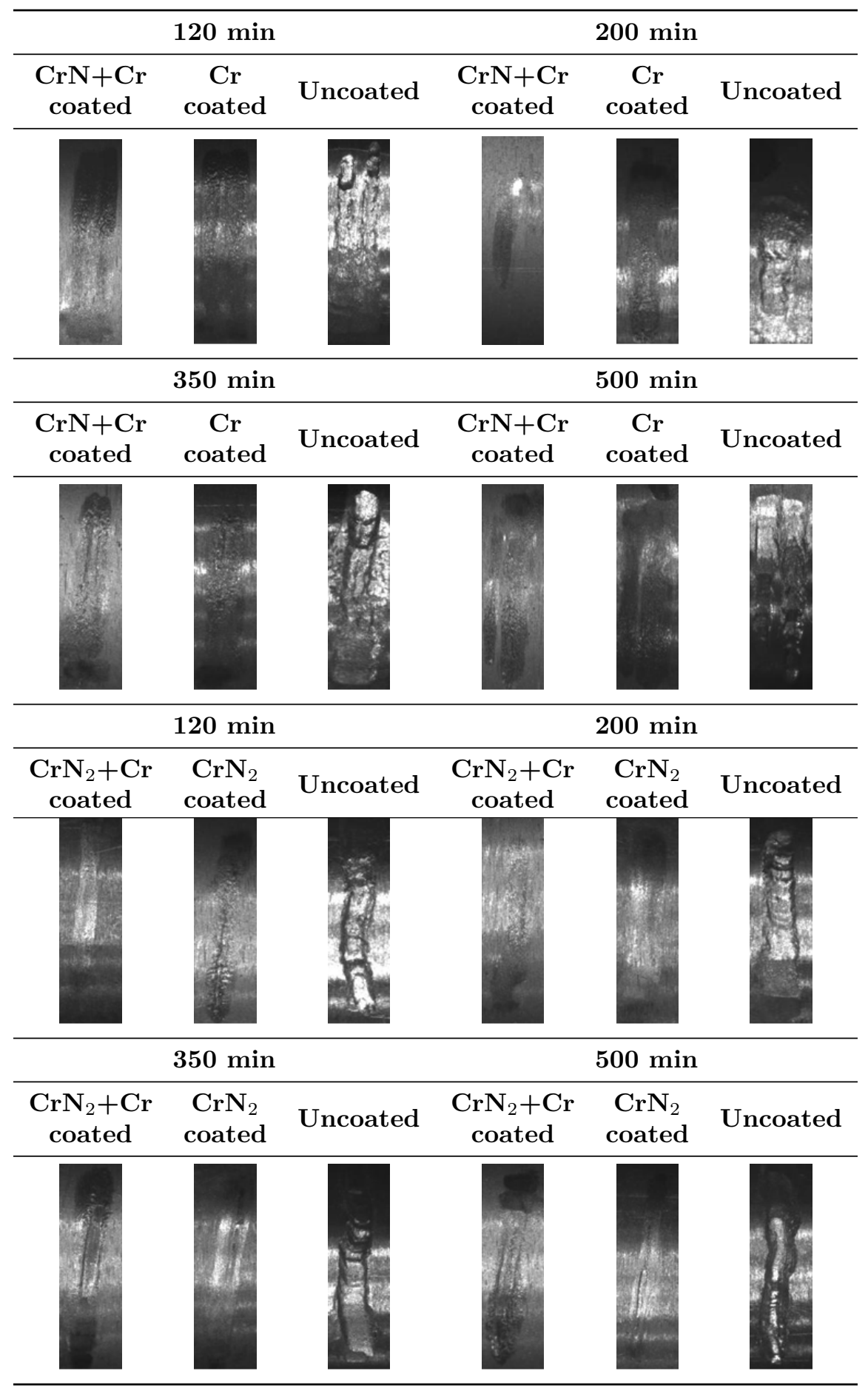


fretting increases with the number of loads, whereas, in the case of coated material, the $\mathrm{Zr}-1 \% \mathrm{Nb}$ matrix seems untouched. High-precision measurements, using replica-method, are planned to specify the real depth of the obtained debris fretting marks. This activity will allow to compare the wear resistance of the coating materials and serve for the qualification reference of the coating in the case of its utilization in the nuclear fuel industry. The powder particle sediment was observed in the vicinity of coated specimens only, with its highest accumulation close to coatings made of $\mathrm{CrN}_{2}+\mathrm{Cr}$ and $\mathrm{CrN}$. The origin of the powder particles is supposed in the surface abrasion of the coating. To investigate the loss of material and friction abilities of the tested coating, the microstructural analysis in the area of fretting marks is planned for later this year. The next steps considered for these specimens are testing at elevated temperatures and testing in water environment. This will bring another data to complete the material resistance against fretting damage. The dry conditions testing is a first step to specify the most promising candidates for future ATF cladding materials. More representative data for direct testing will be obtained from the wet test that can include also more aggressive and corrosive environment.

\section{ACKNOWLEDGEMENTS}

Financial support of this research through ČEZ a.s. company is gratefully acknowledged. Also, this work was supported by the Ministry of Education, Youth and Sport of the Czech Republic, programme NPU1, project No LO1207. The presented work was financially supported by the Ministry of Education, Youth and Sport Czech Republic Project LQ1603 (Research for SUSEN).

\section{REFERENCES}

[1] Nuclear Energy Institute, Nuclear Cost in Context Retrieved March 2016 from: https://www.nei.org/ CorporateSite/media/filefolder/Policy/Papers/ Nuclear-Costs-in-Context.pdf?ext=.pdf, 2016.

[2] The Nuclear News Interview, K. Edsinger. EPRI and the zero fuel failure program Fuel Special Edition, December 2010.

[3] M. Pettigrew. The vibration behavior of nuclear fuel under reactor conditions. Nuclear Engineering and Design 114 pp. 179-189, 1992.

[4] S. Kovács, J. Stabel, M. Ren, B. Ladouceur. Comparative study on rod fretting behavior of different spacer spring geometries. Wear 266 pp. 194-199, 2009.

[5] J. Yan, K. Yuan, E. Tatli, Z. Karoutas. A new method to predict Grid-To-Rod Fretting in a PWR fuel assembly inlet region. Nuclear Engineering and Design 241 pp. 2974-2982, 2011.

[6] K.-T. Kim. A study on the grid-to-rod fretting wearinduced fuel failure observed inthe16x16 KOFA fuel. Nuclear Engineering and Design 240 pp. 756-762, 2010.

[7] J.-K. Park, S.-K. Lee, J.-H. Kim. Development of an evaluation method for nuclear fuel debris-filtering performance. Nuclear Engineering and Technology 50 pp. 738-744, 2018.

[8] J. H. Jackson, D. Paraventi, M. Wright. Proceedings of the 18th International Conference on Environmental Degradation of Materials in Nuclear Power Systems Water Reactors. Portland, USA 2017.

[9] L. Hallstadius, S. Johnson, E. Lahoda. Cladding for high performance fuel. Progress in Nuclear Energy 57:71-76, 2012

[10] E. Lahoda, F. Franceschini. Advanced Fuels for Future Light Water Reactors. Westinghouse Electric Company LLC, Pittsburgh 2011.

[11] K. Barrett, S. M. Bragg-Sitton, D. Galicki. Advanced LWR Nuclear Fuel Cladding System Development Trade-off Study. Idaho National Laboratory 2012. 